BIOMEDICA

Vol. 4, No. 2 - 1984

\title{
CARTAS AL EDITOR
}

Hemos recibido del doctor Francisco Carmona M., las siguientes apreciaciones sobre el artículo "Comportamiento de Anofeles (Kerteszia) lepidotus Zavortink, 1973, y su incriminación como posible vector de malaria en el departamento del Tolima". BIOMEDICA 1984; 1:5.

El período promedio de incubación del $\mathrm{P}$. vivax, es de 14 días, pero se acepta que él pueda prolongarse hasta 8 y 10 meses $^{\star}$. No hay así inconveniente en aceptar el desfase de 2 meses entre picaduras y casos. La correlación de 0.9 obtenida aritméticamente tampoco tiene objección. Mi duda acerca de su validez son 3 valores extremos, uno excepcionalmente alto (picadura 14.75, casos quizá 46) y dos muy bajos (picaduras quizá 2 y 5 , casos por debajo de 10) frente a seis valores casi en línea horizontal (picaduras entre 2 y 8 , casos 16 y 17).

No hay explicación sobre la tasa de picadura excepcionalmente alta en mayo. Pudo ser cuestión de azar.

No aparece el cuadro de las cifras que dieron origen a la figura 2 .

Los gráficos son recursos auxiliares de presentación pero en general ellos no deben sustituir a los datos numéricos, los cuales, entre otros usos, son necesarios para las valoraciones estadísticas.

Si las figuras 2 y 3 se juntan en una sola se facilita la integración visual de los tres fenómenos observados.

No aparece claro si en la localidad de Cunday-Villarrica hay otras especies de Anofeles reconocidas como transmisores del paludismo. La afirmación de que el An. lepidotus es el que muestra mayor y casi único contacto con el hombre, no es científicamente suficiente para descartar la acción de las otras especies. Si las hay cómo se evitó que las personas fueran picadas por esos otros mosquitos?. Si la población estuvo expuesta a esas otras picaduras, así el contacto fuera escaso, la incriminación del lepidotus como posible vector del paludismo que da pendiente de nuevos estudios. No quiero decir que haya que destacarla, solo que hay que comprobarla.

Aunque es de poca transcendencia, el artículo aparece con varios errores quizá de impresión, especialmente en el Sumario en Inglés.

Los comentarios anteriores fueron enviados a los autores del mencionado artículo, quienes ofrecen la siguiente aclaración:

La presentación de la frase "La especie An. lepidotus es la que muestra mayor y casi único contacto con el hombre en este foco" fue inadecuada. Usted tiene razón. Para el planteamiento de la hipótesis de la incriminación de An. lepidotus como posible vector de malaria en este foco se tuvo en cuenta la distribución dentro del Foco CundayVillarrica, el contacto mosquito-hombre y su asociación con la éndemia.

- Independiente de si hay o no "especies de Anopheles reconocidas como transmisores del paludismo" en otro lugar y/o tiempo, pensamos que cada caso debe ser dilucidado en forma particular. Como se menciona en el artículo, en el Foco Cunday-Villarrica. se encontraron otras especies de Anopheles además de An. lepidotus a saber: An. boliviensis, An. argyritaris y An. eiseni.

* OPS/OMS: El control de las enfermedades transmisibles en el hombre. Publicación científica No. 442. Abram S. Benenson, editor. Washington, D C. 1983. 
Con la metodología de colección de ejemplares adultos usada, cualquier Anopheles que se acercara a picar en el intradomicilio o en el peridomicilio de las viviendas fue colectado y posteriormente identificado, así que no se evitó el contacto hombre-mosquito de alguna especie en particular.

Estamos de acuerdo con usted que queden pendientes nuevos estudios. Además de la evidencia epidemiológica, el hallazgo de ejemplares infectados con formas del parásito sería un complemento que fortalece la incriminación de una especie de Anopheles como vector; sin embargo, la interpretación de este hallazgo debe enmarcarse en el contexto epidemiológico particular. El hallazgo de ejemplares infectados no necesariamente da respuesta a la infectividad de una especie, aunque es indiscutiblemente un excelente instrumento auxiliar.
- El hecho de no incluir un cuadro con las cifras que dieron origen a las figuras se hizo en áras de la representatividad y para mantener la visión de conjunto, sin ser repetitivos al presentar la misma información en cuadro y figura. Las cifras están disponibles para su verificación y valoración.

La posibilidad de presentar las figuras 2 y 3 en una sola fue previamente discutida y finalmente concluimos que se diluye la importancia de la figura 2 al integrar en un solo gráfico las dos figuras.

Cordialmente,

(Fdo) MARTHA LUCIA QUINONES Bióloga en Entomología DCD/SEM. 


\section{INSTRUCCIONES PARA LOS AUTORES}

1. Biomédica la revista del Instituto Nacional de Salud recibirá para publicación únicamente artículos originales e inéditos.

2. La revista aceptará artículos que contribuyan a ampliar los conocimientos sobre biomedicina realizadas, tanto en el Instituto Nacional de Salud como en cualquier otro centro investigativo.

Dichos artículos deberán llenar los siguientes requisitos:

a) Ser enviados al editor de la revista, Apartados 80334 y 80080, Zona 6, Bogotá, D.E., Colombia S.A.

b) Ser escritos a máquina, a doble espacio, en original y una copia, dejando márgenes de 4 $\mathrm{cms}$. a la izquierda y $2 \mathrm{cms}$. a la derecha. El original en papel blanco, grueso, tamaño carta.

c) Ser escritos en español con resúmenes en español e inglés.

d) Tener un título conciso. Podrán tener, si fuere necesario, un subtítulo explicativo.

e) Llevar los nombres del autor o los autores inmediatamente después, indicando con asteriscos, en el pié de página, su título académico y la institución en la cual se realizó el trabajo.

f) Incluir en el texto del trabajo: Introducción, Materiales y Métodos, Resultados, Discusión, Conclusiones y Referencias Bibliográficas.

g) Las citas bibliográficas se harán en el texto en forma consecutiva, utilizando números arábigos y deberán aparecer, en el mismo orden numérico de citación. La referencia se presenta así: apellido del autor, seguido de las iniciales de su nombre, título del artículo, nombre abreviado de la revista, año de publicación, volumen, número y pagina .

Ejemplo: Barrow CH. Criptococcosis in animals. J.A. M.A. 1955, 127: 125.

Para la citación de libros se seguirá un orden similar, así: Pearse A., Texbook of Biochemistry. Saunders Edt., 1979; pp 49-50.

h) Los cuadros, gráficas y figuras deben numerarse en forma consecutiva con números arábigos y ser presentados en papel fotográfico brillante, en blanco y negro, manteniendo individualmente una proporción de $2 \times 3$. Dicho material debe ser de calidad y presentación impecables. En hoja aparte se incluirá la leyenda respectiva.

3. La revista también aceptará para publicación: actualizaciones, memorando, revisiones, comunicaciones breves, cartas al editor, revisión de resúmenes e informes técnicos.

4. Todo material propuesto para publicación será revisado por el Comité Editorial. El Editor informará a los autores, tanto sobre la recepción de los trabajos, como sobre la decisión final que se tome.

5. La revista se reservará el derecho de aceptar o rechazar los artículos y podrá hacer sugerencias que tiendan a mejorar su presentación. Para un mejor cumplimiento de esta función el Comité Editorial podrá consultar a especialistas en la materia.

6. Los originales de los artículos publicados permanecerán en los archivos de la revista; aquellos no aceptados para publicación, serán devueltos a sus autores.

7. El autor principal recibirá libre de costo 5 ejemplares de la revista. Los reimpresos deberán ser sufragados por el autor.

NOTA: Las personas interesadas en adquirir la revista podrán hacerlo en la biblioteca del Instituto Nacional de Salud, a un costo de ciento veinticinco pesos m/cte. $(\$ 125.00)$ cada ejemplar, $o$ tomando una suscripción anual. 